\title{
SENSITIVITY OF ACTUAL EVAPOTRANSPIRATION ESTIMATION USING THE SEBS MODEL TO VARIATION OF INPUT PARAMETERS (LST, DSSF, AERODYNAMICS PARAMETERS, LAI, FVC)
}

\author{
N. Abid ${ }^{1}$, C. Mannaerts ${ }^{2}$, Z. Bargaoui ${ }^{1}$ \\ 1: Université de Tunis El Manar, Ecole Nationale d'ingénieurs de Tunis, ENIT, Tunisia - nesrine_abid@ymail.com - \\ zoubeida.bargaoui@laposte.net \\ 2: University of Twente, Faculty of Geo-Information Sciences and Earth Observation (ITC), the Netherlands - \\ c.m.m.mannaerts@utwente.nl
}

KEY WORDS: Actual Evapotranspiration (AET), Surface Energy Balance (SEBS), DSSF, LST, aerodynamics parameters, LAI, Medjerda river basin, Tunisia

\begin{abstract}
:
Actual Evapotranspiration (AET) is a key component of the water and energy balance and hydrological regime of catchments. A land surface energy balance system model (SEBS) was used to estimate the AET of the $160100-\mathrm{km}^{2}$ Medjerda river basin in Northern Tunisia. This model uses satellite data in combination with meteorological data. In this study, we investigated the sensitivity of the AET model output to five major input variables: the 30-minute Downward Surface Shortwave solar radiation fluxes (DSSF), and Land Surface Temperatures (LST), the roughness height for momentum transfer zom, and the influence of the spatial resolution of satellitebased Leaf Area Index (LAI) and fraction of Vegetation Cover (FVC) estimates. The DSSF product was validated using a comparison to solar radiation estimates by the Angstrom formula based on in-situ station data. Gaps in the 15-min satellite-based land surface temperature time series were filled using a sinusoidal model on pixels containing meteorological stations. One-half to two standard deviations of the errors of the regression curves were applied to analyse the sensitivity of the SEBS output. Two methods to estimate the near surface aerodynamic parameter $z_{0 \mathrm{~m}}$ were applied and compared. Maps of LAI and FVC derived from two sensors alternatively applied as an input to the SEBS model. A sensitivity analysis, performed in the first decade of May 2010, showed that SEBS model parameterization is quite sensitive in the forestland cover type. The difference can be up to $0.3 \mathrm{~mm} \mathrm{day}^{-1}$. For agricultural land areas, representing an important percentage of the Medjerda basin, AET estimations based on the SEBS model proved to be used to satisfy the actual evapotranspiration estimates.
\end{abstract}

\section{INTRODUCTION}

Accurate quantification of the amount actual evapotranspiration $(\mathrm{AET})$ is a key element for solving water balance and water use issues in hydrology, agronomy, meteorology and for monitoring the state of the environment such as drought occurrences and water management. Remote sensing provides regular and synoptic observations of vegetation state which are often freely available at different spatial and temporal resolutions (Badola, 2009). In order to estimate AET, several remote sensing based surface energy balance approach [SEBI model (Menenti \& Choudhury, 1993); SEBAL model (Bastiaanssen et al. 1998); ALEXI model (Anderson et al. 1997), S-SEBI model (Roerink et al. 2000); METRIC method (Allen et al. 2007)] are developed.

All the above models use empirical relationships and physical modules from remotely sensed and meteorological data (Gibson et al. 2011). The Surface Energy Balance System (SEBS) developed by Su (2002) solves the land surface energy balance equation by combining satellite data and meteorological data measured in-situ (McCabe et al. 2006). SEBS, which is a part of the free open-source software ILWIS http://www.ilwis.org/, offers the possibility of using satellite data with different spatial resolutions. It is adopted as the initial model of assessment of AET in this research.

SEBS model required several remote sensing data as inputs including the land surface temperature (LST), the downward surface shortwave flux (DSSF), vegetation state (FVC, LAI, NDVI) and the surface albedo. However, the use of these databases is not obvious for many reasons. First, the LST data, which is an important input, is calculated from thermal imagery. The latest along with other spectral band imagery is sensitive to cloud. Consequencely, LST time series data usually contain multitude gaps. Therefore, the model does require filling those gaps by spatial interpolation or fitting through the time series. Second, satellite products as DSSF need to be validated by comparison with estimates obtained from in-situ data. Additionally, to estimate the aerodynamics parameters (canopy height, roughness length for momentum transfer and zero displacement height) of the SEBS model, Normalized Difference Vegetation Index (NDVI) and Leaf Area Index (LAI) maps are required. The latter along with the fraction of vegetation cover (FVC) are inputs to estimate the resistance term $\mathrm{kB}^{-1}$ in order to assess roughness length for the heat transport $\mathrm{z} 0 \mathrm{~d}$ as proposed by $\mathrm{Su}$ et al. (2001). Besides, Fraction of Vegetation Cover (FVC) might be used in SEBS for the surface emissivity (Valor and Caselles 1996), and the soil heat flux estimation ( $\mathrm{Su} \mathrm{2002).}$ Therefore, the quantification of AET by remote sensing data was the subject to several uncertainties (Gibson et al. 2011).

The identification of uncertainties resulting from the different input variables remains a challenge due to the complexity of the parametrization of the open source format of SEBS and the uncertainty of remote sensing data (Gibson et al. 2011). Several studies have investigated sensitivity of SEBS model to the uncertainties of inputs [Su 2002, Gibson et al. 2011; Van der Kwast et al. 2009; Badola, 2009; Timmermans et al. 2011]. Su (2002) found that sensible heat flux $(\mathrm{H})$ was sensitive to land surface temperature and air temperature gradient and to stability correction function for heat transfer. In other studies, it is reported that SEBS model is sensitive to roughness length and to aerodynamics parameters [roughness length, displacement height, and canopy height] (Van der Kwast et al. 2009). The latter used two scenarios to estimate aerodynamics parameters, the empirical scenario, and the field scenario. Van der Kwast et al. 
(2009) found the SEBS model is more sensitive to surface soil temperature than the surface aerodynamic parameters, which is confirmed by Badola (2009). Timmermans et al. (2011) established that uncertainties in the estimation of latent heat via SEBS model were likely due to the uncertainties of incorrect parameterization of the roughness height for the heat transport. According to Gibson et al. (2011), the different variables quantified by remote sensing are subject to uncertainties. They have found that SEBS is sensitive to various variables as fraction vegetation cover, and the reference height of the meteorological station, which is in relation with canopy height and consequently the aerodynamic parameters. Moreover, Gibson et al. (2011) stresses the importance of the choice of the satellite sensor and therefore the pixel resolution and heterogeneity of the study area. These uncertainties are translated to the estimation of actual evapotranspiration. Other studies (Wagle et al. 2017, Bhattarai et al. 2016) have also suggested that SEBS is sensitive to moisture conditions possibly due to improper characterization of $\mathrm{z}_{0 \mathrm{~h}}$. In this context, in order to obtain a good estimation of actual evapotranspiration using SEBS model, sensitivity evaluation of the model output to the variation of several input parameters is carried out.

Therefore, the objective of this research is to focus on the evaluation of possible uncertainties in the pre-package SEBS model in Ilwis environment to some input remote sensing data. This study differs from ordinary sensitivity analysis firstly by using the variation between the remote sensing data DSSF and LST and their mathematical fitting model. In this case, the standard deviation is applied. Then, two approaches are used to estimate roughness length for momentum transfer $\mathrm{z}_{0} \mathrm{~m}$ : the empirical approach based on NDVI map and the land cover approach based on literature. Finally, by using LAI and FVC maps with two different spatial resolutions derived from LSA SAF and SPOT Vegetation products. Still, all the sensitivity analysis of SEBS model to these parameters is based essentially on the daily Actual Evapotranspiration in northern Tunisia (Medjerda Basin).

\section{METHODOLOGY}

These data analysis was done using the ILWIS software environment, which includes the pre-packaged version of SEBS, available from http://52north.org/downloads/ilwis.

\subsection{Surface Energy Balance System (SEBS)}

The SEBS method developed by Su (2002) is one of the remote sensing methods to estimate turbulent surface energy fluxes and evaporative fraction combining remote sensing products and insitu meteorological data. It is based essentially on the energy balance equation:

$$
\mathrm{R}_{\mathrm{n}}=\mathrm{H}+\lambda \mathrm{E}+\mathrm{G}_{0}
$$

Where $R_{\mathrm{n}}$ is the surface net radiation [W $\mathrm{m}^{-2}$ ], $G_{0}$ represents the soil heat flux [W ${ }^{-2}$ ], $\mathrm{H}$ is the turbulent sensible heat flux [W $\left.\mathrm{m}^{-2}\right]$, and $\lambda \mathrm{E}$ is the turbulent latent heat flux $\left[\mathrm{W} \mathrm{m}^{-2}\right]$.

The SEBS model constrains the surface heat flux estimates by considering dry limit ( $\lambda \mathrm{E}$ flux $=0$; soil moisture limitation $)$ and wet limit (potential evaporation; only limited to available energy) conditions, thus limiting the sensible heat flux estimates with an upper and lower boundaries.

\subsection{Method for filling the gaps of land surface temperature (LST)}

Amongst the most important input data in SEBS model is the LST. It is used essentially to calculate net radiation $\left(\mathrm{R}_{\mathrm{n}}\right)$ by Equation (2).

$$
R_{\mathrm{n}}=(1-\alpha) \mathrm{DSSF}+\varepsilon \cdot \varepsilon_{\mathrm{a}} \cdot \sigma \cdot T_{\mathrm{a}}^{4}-\varepsilon . \sigma . \mathrm{LST}^{4}
$$

Where: $\alpha$ is surface albedo map [-], DSSF is the downward surface shortwave flux $\left[\mathrm{w} \mathrm{m}^{-2}\right], \sigma=5.67 * 10^{-8}\left[\mathrm{w} \mathrm{m}^{-2} \mathrm{~K}^{-2}\right]$ is the Stephan Boltzmann constant, $\varepsilon$ is the surface emissivity, LST is the land surface temperature $[\mathrm{K}], T_{\mathrm{a}}$ is the daily air temperature at screen level $[\mathrm{K}], \varepsilon_{\mathrm{a}}$ is the daily apparent emissivity of the atmosphere.

In the present work, LST data are obtained from Land Surface Analysis Satellite Applications Facility (LSA SAF) with a temporal resolution of 15 minute and a spatial resolution of $3 \mathrm{~km}$. We obtain 96 maps of LST per day. For the need of the study, 15-minute data were transformed to daily data by averaging all available LSA SAF LST products for a given day. The presence of clouds results in much missing data points. These gaps can affect the averaging values of LST, therefore, affecting the other terms of the energy balance. Recently many studies were led to fill the land surface temperature time series [Xu et al. 2013; Menenti et al. 1993]. Xu et al. (2013) proposed the harmonic analysis method to reconstruct remotely sensed LST data. They used Modis $1 \mathrm{~km}$ 8-days LST data for the Yangtze River Delta of China and the HANTS algorithm. Xu et al. (2013) extended the HANTS algorithm, initially adopted by Menenti et al. (1993), to remove cloud-contamination values in NDVI time series, to LST time series with good results. This algorithm applies a least squares curve-fitting procedure based on yearly steps and harmonic components. It is the sum of its mean value and several cosine functions with different frequencies (Xu et al. 2013).

$$
\mathrm{y}(\mathrm{t})=a_{0}+\sum_{\mathrm{i}=1}^{\mathrm{N}} a_{\mathrm{i}} \times \cos \left(\omega_{\mathrm{i}} \mathrm{t}-\theta_{\mathrm{i}}\right)
$$

Where $y(t)$ is the fitted curve value at time $t ; N$ is the number of harmonics; $a_{0}$ is the average value of the time series, $a_{i}$ is the amplitude of harmonic $i$; $\omega_{i}$ is the frequency of harmonic $i$; and $\theta_{\mathrm{i}}$ is the phase of harmonic $\mathrm{i}$.

In our case study, we need to fill the gaps of LST time's series on daily steps. Therefore, we adopt the sum of sinus function available on the Matlab environment:

$$
y(t)=\sum_{i=1}^{N} a_{i} \times \sin \left(b_{i} t+c_{i}\right)
$$

Where $y(t)$ is the fitted LST curve value at time $t ; N$ is a number of harmonics; $a_{i}$ is the amplitude of harmonic $\mathrm{i} ; b_{i}$ is the frequency of harmonic $\mathrm{i}$; and $c_{i}$ is the phase of harmonic $\mathrm{i}$.

The least square method is adopted to estimate $a_{i}, b_{i}$, and $c_{i}$ for various assumptions on $\mathrm{N}$. To select the best $\mathrm{N}$ value, the evaluation of the result is based on the following statistical criterion: sum of squares due to error ( $S S E)$, R-square and the adjusted R-square statistic, root mean squared error (RMSE). A value closer to zero of SSE indicates that the model has a smaller random error component. For R-square and the adjusted Rsquare, a value closer to one indicates that the model accounts for a greater proportion of variance. A RMSE value closer to 0 indicates a better fit.

The time series of land surface temperature (LST-LSA SAF) contain too many gaps (more than 30 ) for some days. Thereby, the identification of the sinusoidal regression is based only on days including less than 30 gaps (using at least 66 observations) per day and per pixel including a meteorological station. Therefore, the selected days of the first decade of May 2010 are: $1,5,6,8,9$ and 10 . 


\subsection{Method for validating of DSSF estimation using daily in-situ data}

The downward surface shortwave flux is an important input data in SEBS model as it is used to calculate the net radiation $R_{\mathrm{n}}$ (Equation 2). In the present work, DSSF data were obtained from Land Surface Analysis Satellite Applications Facility (LSA SAF) with a temporal resolution of 30 minutes and the same spatial resolution as LST ( $3 \mathrm{~km}) .48$ maps of DSSF per day are obtained. The method of temporal averaging consists of calculating the average directly with statistical function in Ilwis: this method considers all values in the time even those that are undefined. The latter is assumed null because they occur night-time.

After averaging of the 30-minute DSSF maps, the daily DSSF estimations are compared with values calculated based on in-situ observations. To this end, the pixels to which belong meteorological stations are evaluated. The Angstrom formula (model) (Allen et al. 1998) was used to estimate the solar radiation using in-situ data at the level of the meteorological station. It is based on extraterrestrial radiation estimation and relative sunshine duration observation (Allen et al. 1998, Irmak et al. 2005). This equation adopts the in-situ meteorological actual duration of sunshine as well as station latitude as input variables:

$$
R_{\mathrm{s}}=\left(\mathrm{a}_{\mathrm{s}}+\mathrm{b}_{\mathrm{s}} \times \frac{\mathrm{n}}{\mathrm{N}}\right) \mathrm{R}_{\mathrm{a}}
$$

$R_{\mathrm{s}}$ solar or shortwave radiation [ $\mathrm{MJ} \mathrm{m}{ }^{-2}$ day $^{-1}$ ], $\mathrm{n}$ actual daylight hours [hour], N maximum possible duration of sunshine [hour]:

$$
\mathrm{N}=24 / \pi \omega_{\mathrm{s}}
$$

$\mathrm{n} / \mathrm{N}$ relative sunshine duration [-], $a_{\mathrm{s}}$ regression constant, expressing the fraction of extraterrestrial radiation reaching the earth on overcast days $(\mathrm{n}=0), a_{\mathrm{s}}+b_{\mathrm{s}}$ fraction of extraterrestrial radiation reaching the earth on clear days $(n=N), \omega_{s}$ is the sunset hour angle. The values $a_{\mathrm{s}}=0.25$ and $b_{\mathrm{s}}=0.50$ are recommended to our study area (Allen et al.1998). $R_{\mathrm{a}}$ extraterrestrial radiation [MJ m${ }^{-2}$ day $^{-1}$ ]:

$$
\begin{gathered}
\mathrm{R}_{\mathrm{a}}=\mathrm{G}_{\mathrm{sc}} \mathrm{d}_{\mathrm{r}}\left[\omega_{\mathrm{s}} \sin (\varphi) \sin (\delta)+\cos (\varphi) \cos (\delta) \sin \left(\omega_{\mathrm{s}}\right)\right](7) \\
\mathrm{d}_{\mathrm{r}}=1+0.33 \cos \left(\frac{2 \pi}{365} \mathrm{~J}\right) \\
\omega_{\mathrm{s}}=\operatorname{arcos}-[\tan (\varphi) \tan (\delta)] \\
\delta=0.409 \sin \left(\frac{2 \pi}{365} \mathrm{~J}-1.39\right)
\end{gathered}
$$

$G_{\text {sc }}$ solar constant $=0.0820\left[\mathrm{MJ} \mathrm{m}{ }^{-2} \mathrm{~min}^{-1}\right], d_{\mathrm{r}}$ inverse relative distance Earth-Sun, J latitude [rad], $\omega_{\mathrm{s}}$ sunset hour angle [rad], $\delta$ Solar decimation [rad]

The evaluation of results is based on the coefficient of determination $\left(R^{2}\right)$ of the regression between satellite estimation at the pixel level and the Angstrom model estimation at the station level. Daily values are compared for each month separately to take into account the seasonal variation of solar radiation.

\subsection{Method of sensitivity of SEBS model}

2.4.1 Land Surface Temperature (LST): To detect the sensitivity of actual evapotranspiration (AET) via SEBS to the variation of land surface temperature (LST), the variance of error of the sinusoidal regression and the LSA SAF product is used at the level of the meteorological station. For each day, a range of standard deviation is fixed and four tests of sensitivity applied: \pm $1 / 2$ standard deviation and \pm 1 standard deviation to the land surface temperature derived from LSA SAF product. These latter are used separately as inputs in SEBS model.
2.4.2 Downward Surface Short waves Flux (DSSF): In order to evaluate the sensitivity of SEBS model, the regression residuals time series were investigated in each station to identify firstly the variance of the daily residual of each series and then the standard deviation per month and per station. Maps of the standard deviation residuals were established using spatial moving average under Ilwis. Six maps of bounded DSSF were developed by mapping DSSF $\pm 1 / 2 *$ Std where Std is standard deviation and DSSF $\pm 1 *$ Std and DSSF $\pm 2 *$ Std. As result, seven maps of shortwave flux were used: DSSF, DSSF \pm the errors interval based on the standard deviation (6 maps) and integrated as inputs to SEBS.

2.4.3 The height of vegetation $h$, roughness height for momentum transfer $\mathrm{z}_{0 \mathrm{~m}}$ and zero plane displacement $\mathrm{d}_{0}$ : $\mathrm{A}$ multitude of studies indicates the sensitivity of SEBS model to the surface roughness for momentum transfer $z 0 \mathrm{~m}$ and zero-plane displacement $d_{0}$ (Gibson et al. 2011; Timmermans et al. 2011) which are used in the determination of the sensible heat flux $\mathrm{H}$. According to $\mathrm{Su}$ (2002), the sensible heat $\mathrm{H}$ is calculated in two limits (wet and dry) using Equation (11) and (12) respectively.

$$
H_{\text {wet }}=\left[\left(\mathrm{R}_{\mathrm{n}}-\mathrm{G}_{0}\right)-\frac{\rho \mathrm{C}_{\mathrm{p}}}{\mathrm{r}_{\mathrm{ew}}} \times \frac{\mathrm{e}_{\mathrm{s}}-\mathrm{e}}{\gamma}\right] /\left(1+\frac{\Delta}{\gamma}\right)
$$

$$
\mathrm{H}_{\text {dry }}=\mathrm{R}_{\mathrm{n}}-\mathrm{G}_{0}
$$

With $\mathrm{e}$ and $\mathrm{e}_{\mathrm{s}}$ are actual and saturation vapor pressure respectively, $\gamma$ is the psychrometric constant, $r_{\mathrm{ew}}$ is the external resistance at the wet limit and $\Delta$ is the rate of change of saturation vapor pressure with temperature.

When the two limits are not reached, Equations (13), (14) and (15) are solved iteratively for estimating $\mathrm{H}$.

$$
\begin{gathered}
\mathrm{u}(\mathrm{z})=\frac{\mathrm{u}_{*}}{\mathrm{k}}\left[\ln \left(\frac{\mathrm{z}-\mathrm{d}_{0}}{\mathrm{z}_{0 \mathrm{~m}}}\right)-\Psi_{\mathrm{m}}\left(\frac{\mathrm{z}-\mathrm{d}_{0}}{\mathrm{~L}}\right)+\Psi_{\mathrm{m}}\left(\frac{\mathrm{z}_{0 \mathrm{~m}}}{\mathrm{~L}}\right)\right] \\
\theta_{0}-\theta_{\mathrm{a}}=\frac{\mathrm{H}}{\mathrm{ku}_{*} \rho \mathrm{C}_{\mathrm{p}}}\left[\ln \left(\frac{\mathrm{z}-\mathrm{d}_{0}}{\mathrm{z}_{\mathrm{oh}}}\right)-\Psi_{\mathrm{h}}\left(\frac{\mathrm{z}-\mathrm{d}_{0}}{\mathrm{~L}}\right)+\Psi_{\mathrm{h}}\left(\frac{\mathrm{z}_{0 \mathrm{~h}}}{\mathrm{~L}}\right)\right] \\
\mathrm{L}=\frac{\rho \mathrm{C}_{\mathrm{p}} \mathrm{u}_{*}^{3} \theta_{\mathrm{v}}}{\mathrm{kgH}}
\end{gathered}
$$

Where $\mathrm{u}$ is the wind speed $\mathrm{z}$ is the height above the surface $\mathrm{u} *$ is the friction velocity, $\mathrm{k}=0.4$ is von Karman constant, $\mathrm{d}_{0}$ is displacement height. $\theta_{0}$ is the potential temperature at the surface, $\theta_{a}$ is the potential air temperature at height $\mathrm{z}, \mathrm{zoh}$ is the scalar height for heat transfer, $\Psi_{m}$ and $\Psi_{h}$ are the stability correction functions for momentum and sensible heat respectively. $L$ is the Obukhov length, $g$ is acceleration due to gravity and $\theta_{v}$ is the potential virtual temperature near the surface (Su 2002).

If the sensible heat $\mathrm{H}$ calculated with the latter Equations (13) (15) is beyond the $\mathrm{H}_{\mathrm{dry}}$, the dry limit is reached and Equation (12) is used to determine $\mathrm{H}$. If it is below the $\mathrm{H}_{\text {wet }}$ calculated by Equation (11), the wet limit is reached and $\mathrm{H}=\mathrm{H}_{\text {wet }}$.

$\mathrm{z}$ in Equation (13) and (14) is often taken as the elevation at which meteorological data (wind speed, air temperature, etc.) are measured. Here, we have in-situ observations at $\mathrm{z}=2 \mathrm{~m}$. In the pre-packaged SEBS model, the height of vegetation $h$, the roughness height $\mathrm{z}_{0 \mathrm{~m}}$, and displacement height $\mathrm{d}_{0}$ can be identified by two approaches. The first approach (a) is a result of interpretation of the land cover map (PELCOM; Pan-European Land Use and Land Cover Monitoring) (Chameaux et al. 2000). The second approach (b) uses an empirical function based on the NDVI map [the methodology adopted by $\mathrm{Su}$ (2002), Timmermans et al. 2011, and Van der Kwast et al. 2009]. 
A drawback of approach (a) is that northern Tunisia (including Medjerda basin) is covered in a large part by forests and agricultural lands including olive groves which olive trees height exceeds $3 \mathrm{~m}$ and consequently the attributed $\mathrm{d}_{0}>2 \mathrm{~m}$. Now, as described in $\mathrm{Su}$ (2002), the sensible heat is calculated using the Equation (12) - (14) and the difference ( $\left.\mathrm{z}-\mathrm{d}_{0}\right)$ becomes negative when the displacement height $\left(\mathrm{d}_{0}\right)$ exceeds $2 \mathrm{~m}$ (the Natural Logarithm cannot be solved in Equation (13) and (14)). Gibson et al. (2011) have found the same problem in the Western Cape Province of South Africa and they tested the sensitivity of daily AET to $d_{0}$. They found that with approximately $d_{0}=1.8 \mathrm{~m}$ a rapid decrease of daily ET estimation is noticed. For regions where the vegetation is taller than $2.7 \mathrm{~m}$ and the reference height is about 2 $\mathrm{m}$, the SEBS model becomes highly sensitive to changes of $d_{0}$ according to Gibson et al. (2011). To overcome this difficulty, wind speed in Equation (13) is introduced at $\mathrm{z}=10 \mathrm{~m}$ using the empirical Log law (Irmak et al. 2005):

$$
\mathrm{u}=\mathrm{u}_{2 \mathrm{~m}} \times \frac{\ln \frac{\mathrm{z}}{\mathrm{z}_{0}}}{\ln \frac{\mathrm{z}_{\mathrm{ref}}}{\mathrm{z}_{0}}}
$$

With: $\mathrm{u}=$ velocity at $\mathrm{z}, \mathrm{z}=10 \mathrm{~m}, \mathrm{u}_{2 \mathrm{~m}}=$ velocity at height $z_{\text {ref }}$, zref $=2 \mathrm{~m}$ reference height, $z_{0}=$ roughness length in the current wind direction.

In the second approach (b), $z_{0 \mathrm{~m}}$ and $d_{0}$ are estimated from a remote sensing vegetation input, which is the NDVI and LAI maps using the following empirical model (Su et al. 2001).

$$
\mathrm{z}_{0 \mathrm{~m}}=0.005+0.5\left(\frac{\mathrm{NDVI}}{\mathrm{NDVI}_{\max }}\right)^{2.5}
$$

The estimation of $z 0 \mathrm{~m}$ (from literature or Equation 17) results in the estimation of the vegetation height (h) (Equation 18) (Brutsaert 1982) and then it is used to derive the zero plane displacement height $\left(d_{0}\right)$ (Su et al. 2001) needed in Equation (13) and (14).

$$
\begin{array}{r}
\mathrm{h}=\frac{\mathrm{z}_{0 \mathrm{~m}}}{0.136} \\
\mathrm{~d}_{0}=\left(1-\frac{1}{2 \mathrm{n}_{\mathrm{h}} \times\left(1-\mathrm{e}^{\left.-2 \mathrm{n}_{\mathrm{h}}\right)}\right)} \times \mathrm{h}\right.
\end{array}
$$

With:

$$
\mathrm{n}_{\mathrm{h}}=0.2 \times \frac{\mathrm{LAI}}{2 \times\left(0.32-0.26 \times \mathrm{e}^{-3.05 \times \mathrm{LAI}}\right)^{2}}
$$

The estimated values of $d_{0}$ should be less than the level $\mathrm{z}$. Otherwise, Equations (13) and (14) are unsolved. AET maps resulting from the two approaches are compared.

To evaluate the sensitivity of SEBS model to $\mathrm{z}_{0 \mathrm{~m}}$, the results of actual evapotranspiration estimated using separately the two methods of roughness height for momentum transfer estimation are aggregated per land cover. Indeed, the variation of the roughness of momentum height $\mathrm{z} 0 \mathrm{~m}$ is compared to the variation of actual evapotranspiration $\Delta$ AET by land cover.

2.4.4 Vegetation inputs Leaf Area Index (LAI) and Fraction of Vegetation Cover (FVC): These vegetation inputs data are used in SEBS model and they play a crucial role in the process of calculating in the SEBS model. Data are used from two different sources: the first from LSA SAF with daily temporal resolution and $3 \mathrm{~km}$ spatial resolution. The second source is the SPOT vegetation with higher spatial resolution $(1 \mathrm{~km})$ and decadal temporal resolution. We have used the two different spatial resolutions of vegetation input (LAI and FVC) in SEBS model. The LSA SAF LAI and FVC products are resampled from $3 \mathrm{~km}$ to $1 \mathrm{~km}$ under Ilwis using the nearest neighbour method. We highlight the effect of downscaling the vegetation input on the estimation of actual evapotranspiration.

\section{STUDY AREA}

The study area is the Medjerda basin in Tunisia, which is crossed by the Medjerda River, flowing from Algeria into the Gulf of Tunis and in the Mediterranean Sea (Figure 1). The climate of the study area is subject to Mediterranean, North Atlantic as well as continental Sahara influences. It is in fact divided into humid, sub-humid and semi-arid zones from north to south. A variety of forests, grasslands and agricultural practices areas cover the study region.

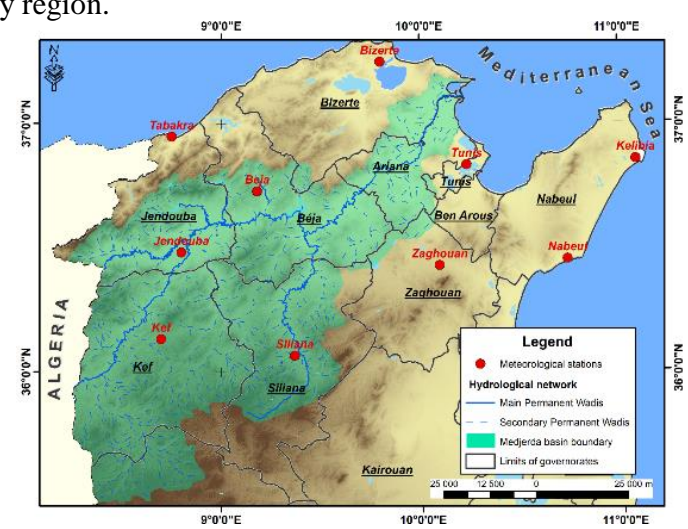

Figure 1. Location of meteorological stations in the north of Tunisia with governorates administrative limits and Medjerda basin boundary.

\subsection{Meteorological data}

To run SEBS model we need to provide meteorological data and remote sensing data. Meteorological in-situ data are air temperature, air pressure and relative air humidity, sunshine duration and wind speed. They were provided by the National Institute of Meteorology (INM) in Tunis (www. meteo.tn). We used time series data from ten weather stations scattered in northern Tunisia: Tunis, Nabeul, Bizerte, Kelibia, Kef, Jendouba, Siliana, Tabarka, Zaghouan and Beja (Figure 1). These stations cover the meteorological network of northern Tunisia. These data were daily all along the year 2010. Figure 2 describes the variation of monthly average air temperature and monthly average daylight hours in the study area for the year 2010. It highlights the trend of air temperature and actual duration of sunshine. The highest value of average air temperature is about $30{ }^{\circ} \mathrm{C}$ and about 13 hours for the actual duration of sunshine, which corresponds to the summertime [July and August].

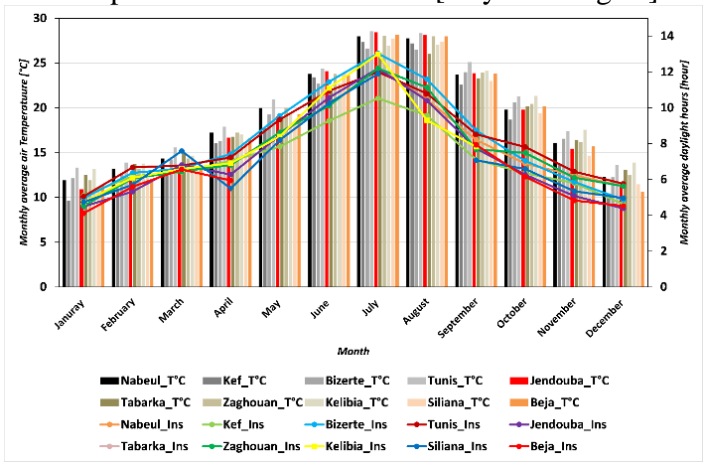

Figure 2. Monthly average air temperature $\left[{ }^{\circ} \mathrm{C}\right]$ and actual duration of sunshine [hour] in the 10 meteorological stations included in the Medjerda Basin for the year 2010.

\subsection{Remote sensing data}

SEBS requires several bio-geophysical satellite data sets (Table $1)$, such as elevation and land surface characteristics. The topographic information (DEM) was obtained from 
http://eros.usgs.gov/\#/Find_Data/Products_and_Data_Availabl e/gtopo30_info; land surface and cover information (e.g. land surface temperature LST, etc.) were obtained from the LSA SAF (https://landsaf.meteo.pt). Time series of vegetation was further obtained from SPOT Vegetation data, available from http://free.vgt.vito.be/. The land cover map is downloaded from Glob Cover 2009 that have been processed by ESA http://due.esrin.esa.int/page_globcover.php. Global Land Cover Map released on $21^{\text {st }}$ December 2010. For each type of data, temporal and spatial resolution, as well as, data sources are reported in Table 1.

\begin{tabular}{|l|c|c|c|c|}
\hline Parameters & $\begin{array}{c}\text { Temporal } \\
\text { resolution }\end{array}$ & $\begin{array}{c}\text { Spatial } \\
\text { resolution }\end{array}$ & $\begin{array}{c}\text { Source } \\
\text { of data }\end{array}$ & Unit \\
\hline \multirow{2}{*}{ LST } & $\begin{array}{c}15 \mathrm{~min} \rightarrow \\
\text { daily }\end{array}$ & $3 \mathrm{~km}$ & MSG & {$\left[{ }^{\circ} \mathrm{C}\right]$} \\
\hline Albedo & Daily & $3 \mathrm{~km}$ & MSG & {$[-]$} \\
\hline \multirow{2}{*}{ FVC } & Daily & $3 \mathrm{~km}$ & MSG & {$[-]$} \\
\cline { 2 - 5 } & Decadal & $1 \mathrm{~km}$ & SPOT & {$[-]$} \\
\hline \multirow{2}{*}{ LAI } & Daily & $3 \mathrm{~km}$ & MSG & {$[-]$} \\
\cline { 2 - 5 } & Decadal & $1 \mathrm{~km}$ & SPOT & {$[-]$} \\
\hline \multirow{2}{*}{ DSSF } & $\begin{array}{c}30 \text { min } \rightarrow \\
\text { daily }\end{array}$ & $3 \mathrm{~km}$ & MSG & {$\left[\mathrm{W} / \mathrm{m}^{2}\right]$} \\
\hline DEM & - & $90 \mathrm{~m}$ & STRM & {$[\mathrm{m}]$} \\
\hline NDVI & Decadal & $1 \mathrm{~km}$ & SPOT & {$[-]$} \\
\hline
\end{tabular}

Table 1. Satellite data used as inputs in the SEBS model.

\section{RESULTS AND DISCUSSION}

\subsection{Filling the gaps of land surface temperature maps}

An example of the fitted model is shown in Figure 3 for 6 May 2010 obtained with 2 harmonics at Siliana, Jendouba, Beja and Kef stations. The $R^{2}$ values are assumed acceptable varying between 0.8 and 0.9. Therefore, there is a good agreement between the fitted models and remote sensing LST data. Then, the standard deviation of regression errors is estimated for each station in order to draw the AET sensitivity maps. Values differ from day to day and from station to station generally, it vary between 0.6 and 2.2 .

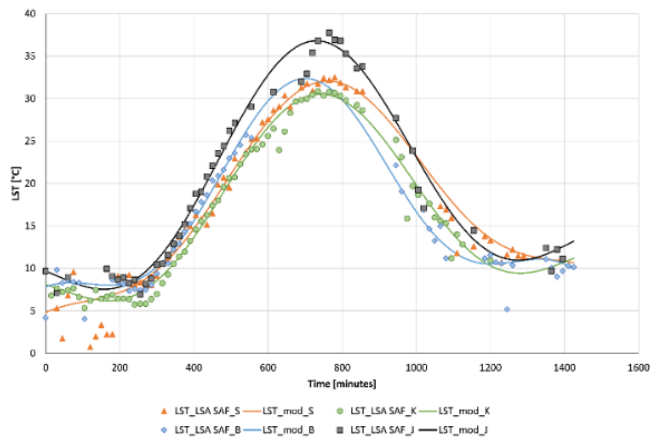

Figure 3. Example of fitted and original LST time series on the Beja (B), Jendouba (J), Siliana (S) and Kef (K) stations for May 6, 2010.

\subsection{Validation of Downward Surface Shortwave Flux LSA SAF product with daily in-situ data}

In Figure 4 DSSF values calculated for all days of (a) January, (b) March, (c) May and (d) July 2010 are reported in comparison to those for LSA SAF data. A linear regression is found between the two variables with the coefficient of determination $R^{2}$ ranging from [0.5, 0.9], showing a good agreement between the DSSF LSA SAF product and the in-situ estimation. The standard deviations of errors were between $\left[9,16 \mathrm{~W} \mathrm{~m}^{-2}\right]$ for January , [25, $\left.45 \mathrm{~W} \mathrm{~m}^{-2}\right]$ for March. For May the standard deviation is [19, 33 $\left.\mathrm{W} \mathrm{m}^{-2}\right]$ and $\left[8,16 \mathrm{~W} \mathrm{~m}^{-2}\right]$ for July 2010 .

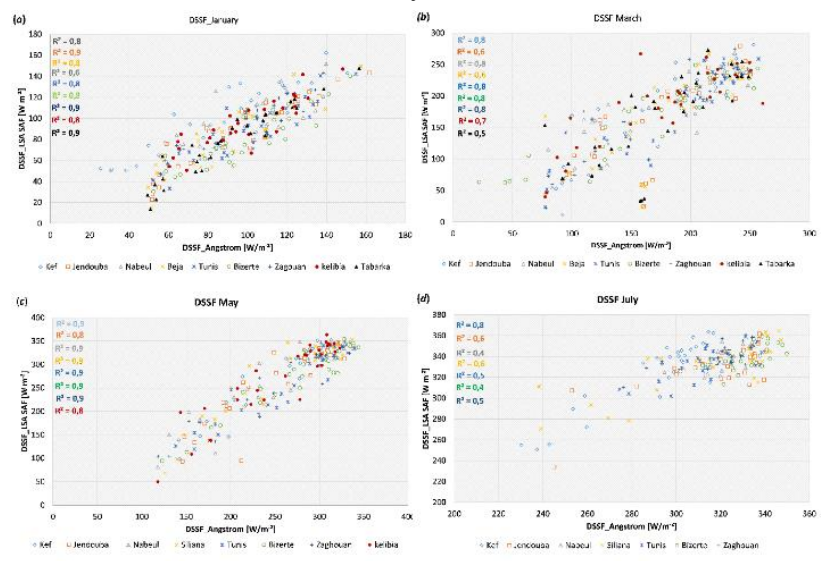

Figure 4. Scatter plot of daily DSSF LSA SAF and $\mathrm{R}_{\mathrm{S}}$ calculated by Angstrom formula for (a) January, (b) March, (c) May and, (d) July 2010.

\subsection{Sensitivity study of SEBS model}

The sensitivity analysis of SEBS model for the DSSF and LST inputs was performed for the selected days of the first decade of May. For $\mathrm{z}_{0} \mathrm{~m}, \mathrm{LAI}$, and FVC, the analysis was established for a single day 6 May 2010.

\subsubsection{Sensitivity to Land Surface Temperature (LST):}

If we assume, at station scale a change of $\pm 1 / 2$ standard deviation of errors in land surface temperature estimation and then, a change of \pm one standard deviation, Figure 5 shows the resulting changes in AET. Firstly, the graph shows that for $1 / 2$ Standard deviation change in LST $\left[0.5,1.2{ }^{\circ} \mathrm{C}\right]$ we obtain a bias of AET $\leq 1 \mathrm{~mm}$ day $^{-1}$. However, for 1 standard deviation change, the actual evapotranspiration shows a variation between $[0.6,2 \mathrm{~mm}$ day $^{-1}$ ]. Therefore, the lower bound remains unchanged while the upper bound results in a huge change. Further, Figure 5 highlights a negative relationship between change in land surface temperature and in actual evapotranspiration: with decreasing of land surface temperature, an increasing of actual evapotranspiration is resulting. However, for some stations in some days, AET decreases as LST decreases. These variations can be explained based on SEBS formulation. Effectively, evapotranspiration is estimated based on the evaporative fraction by setting a wet and dry limit. The positive trend can be explained in relation with the Equation (11): with decreasing of LST, the denominator is decreased by the decrease in the rate of change of saturation vapor pressure with temperature and therefore the sensible heat flux at the wet limit increases and the latent heat at the wet limit decreases. As result, the fraction of evaporation decreased and consequently, actual evapotranspiration decreased. Conversely, if the wet-limit is not reached, Equations (13)-(15) are used to calculate the sensible heat flux. With decreasing of land surface temperature in Equation (14), a decrease of sensible heat flux is obtained and therefore an increase of the latent heat flux and of the fraction of evaporation. As explained by Horvat (2013), if the wet limit is not reached, available soil moisture decreases in the root zone. In this case, the stomata close up and transpiration decreases. As consequence, the soil heats up faster and more of the available energy is used to raise the surface temperature. Therefore, the actual evapotranspiration decreases.

We conclude that the variation of land surface temperature by \pm $1 / 2$ standard deviation (maximum $1{ }^{\circ} \mathrm{C}$ ) leads to a small variation of AET does not exceed $0.5 \mathrm{~mm} \mathrm{day}{ }^{-1}$. The observed soil 
temperature could lead to a better appreciation of the quality of these results.

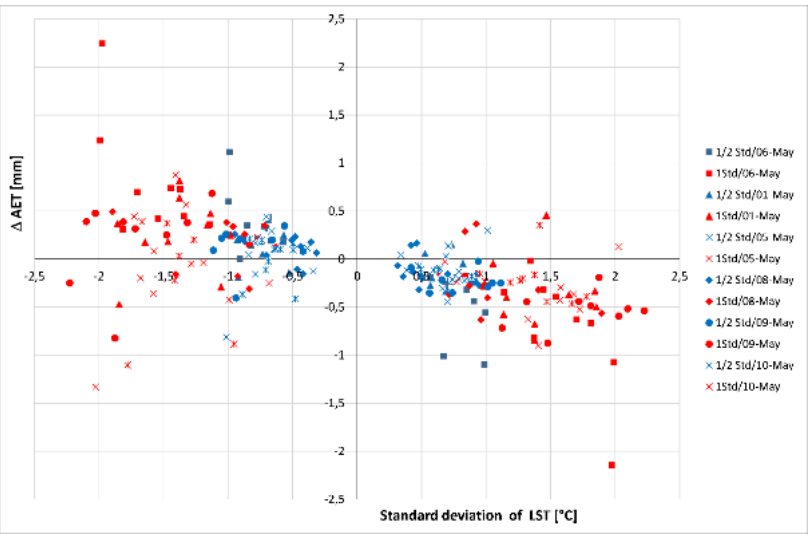

Figure 5. Changes of actual evapotranspiration (AET) against the changes of land surface temperature (LST) input by one-half standard deviation and 1 standard deviation for several selected days within the first decade of May 2010. (Meteorological stations are merged).

\subsubsection{Sensitivity of AET to Downward Surface Short} waves Flux (DSSF): We do compare in Figure 6 the change of daily SEBS actual evapotranspiration resulting from a change in downward surface shortwave flux (DSSF) for meteorological stations for the first decade of May 2010. It highlights that for a change of $\left[ \pm 10,33 \mathrm{~W} \mathrm{~m}^{2}\right]$ representing $1 / 2$ standard deviation, the actual evapotranspiration varies by $0.1 \mathrm{~mm} \mathrm{day}^{-1}$. For a higher variation $\left[ \pm 40,66 \mathrm{~W} \mathrm{~m}^{-2}\right]$ representing +1 standard deviation, the variation of AET can reach 0.2 and $0.3 \mathrm{~mm} \mathrm{day}^{-1}$. This result indicate that the AET is not sensitive to DSSF variation (about $70 \mathrm{~W} \mathrm{~m}^{2}$ ). In addition, the variation of AET versus the variation of DSSF describes a negative trend. AET decreases as DSSF increases. In effect, with increasing DSSF, net radiation increases and as consequence, the sensible heat flux increases. As a result, evaporative fraction, which is the ratio of latent heat to available energy, decreases. This can explain the diminution of actual evapotranspiration values.

As a conclusion, even if one makes a DSSF error of 1 standard deviation (about $70 \mathrm{~W} \mathrm{~m}^{-2}$ ), the AET is not sensitive.

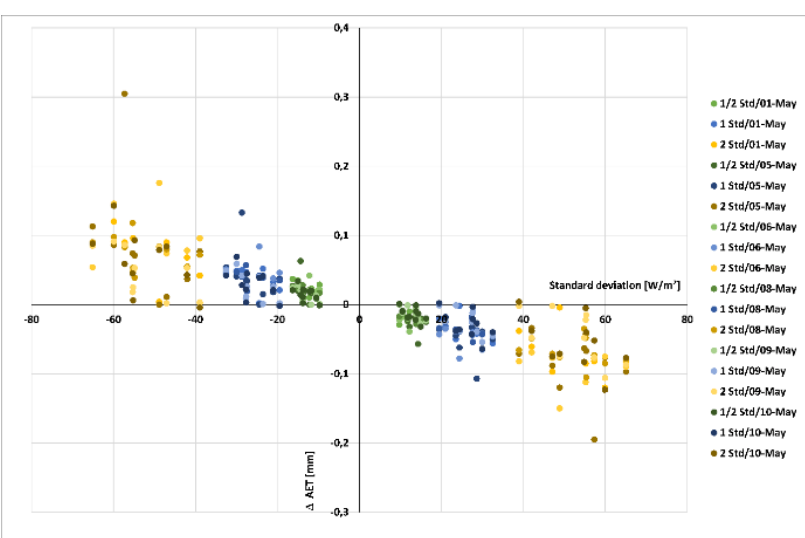

Figure 6. Change of actual evapotranspiration (AET) against the change of DSSF input by one-half standard deviation, 1 standard deviation and 2 standard deviations for several selected days within the first decade of May 2010.

4.3.3 Sensitivity to the roughness height for momentum transfer $z_{0 m}$ : First, we analyze the $z_{0 m}$ variability. The map (Figure 7) shows the bias of $\mathrm{z} 0 \mathrm{~m}$ when estimated by the two approaches from land use classification (a) and from empirical equation (b). It highlights smaller $\mathrm{z}_{0 \mathrm{~m}}$ in most parts of the study area for the approach related to the use of the NDVI regression (b). The mapped mean bias between methods is $-0.3 \mathrm{~m}$ with a standard deviation equal to $0.18 \mathrm{~m}$. Aggregated bias per land cover indicates that the most important bias is about $-1 \mathrm{~m}$ and is related to the forest type land cover. A mean bias of $-0.45 \mathrm{~m}$ is identified in rainfed cropland and shrubland (code 10).

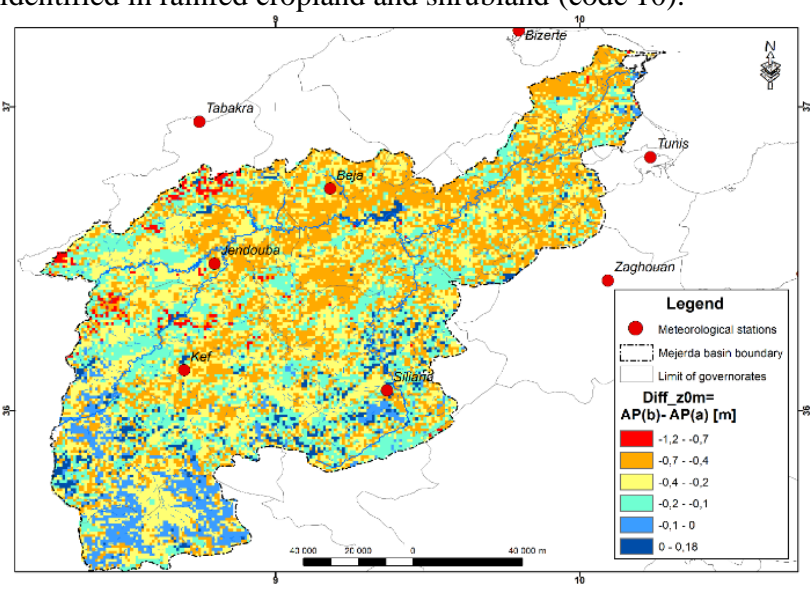

Figure 7. Map of the difference between roughness heights for momentum transfer $\mathrm{z} 0 \mathrm{~m}$ estimated using two approaches: $\mathrm{z} 0 \mathrm{~m}$ estimated from empirical equation (b) minus zom estimated from land use classification (a) in Medjerda basin on 6 May 2010.

Figure 8 highlights that the greater change of AET, which varies between $\left[-1,-2 \mathrm{~mm} \mathrm{day}^{-1}\right]$, is observed for the forestlands. All the other land cover except water bodies are characterized by a variation which lays between $\left[-0.5,0.5 \mathrm{~mm}^{-1 a y}{ }^{-1}\right]$. In general, Figure 8 suggests a positive trend between actual evapotranspiration (AET) changes and roughness for momentum height $\left(\mathrm{z}_{0} \mathrm{~m}\right)$ changes: AET decreases as $\mathrm{z}_{0 \mathrm{~m}}$ decreases.

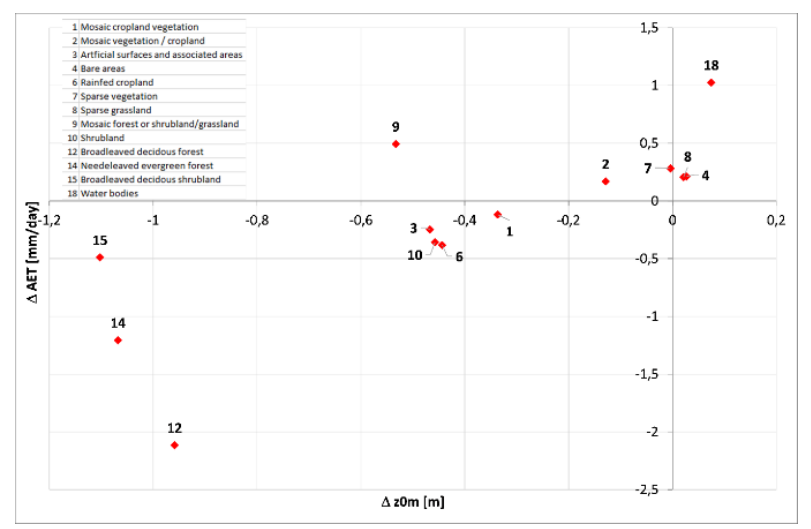

Figure 8. Scatter plot of AET change against roughness height for momentum transfer change by land cover types due to shifting from $\mathrm{z} 0 \mathrm{~m}$ derived from PELCOM to empirical $\mathrm{z} 0 \mathrm{~m}$ using Spot NDVI map for May 6, 2010 in Medjerda Basin.

Figure 9 shows the results aggregated per land cover. It notices the most important overestimation of AET values at the level of forestland (code 12 and 14) when using PELCOM data instead of applying empirical equation by using NDVI data.

The result shows that the actual evapotranspiration estimated by the SEBS model is very sensitive to the value of $\mathrm{z}_{0} \mathrm{~m}$. We go up to $2 \mathrm{~mm}$ in absolute value. According to our results linked to 1 $\mathrm{km}$ resolution, it seems that the differences in AET are mostly linked to land use type: they are more significant for the forests type land cover compared to other types. 


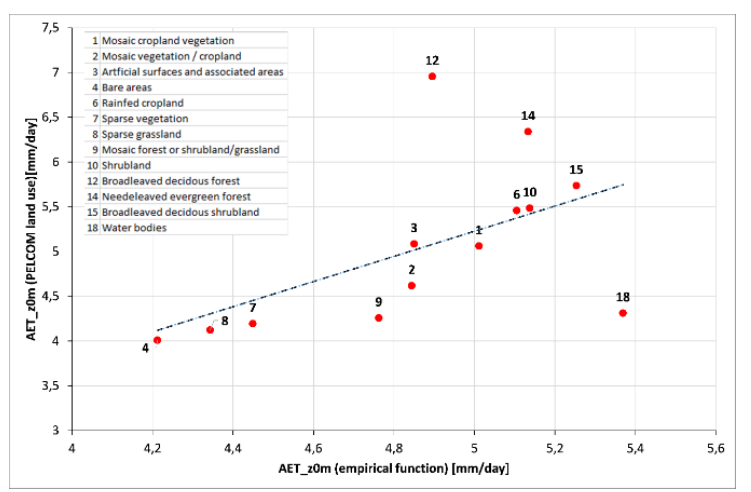

Figure 9. Scatter plot of AET estimated using separately the two approaches (empirical function and land cover classification) to determine roughness height for momentum transfer and aggregated by land cover in Medjerda basin on May 6, 2010.

4.3.4 Sensitivity to the variation of vegetation inputs (LAI and FVC) : When $\Delta \mathrm{LAI}, \Delta \mathrm{FVC}$ and $\Delta \mathrm{AET}$ are aggregated by land use (Figure 12), it is found that the sensitivity of AET to a change in LAI is very small for all land cover types and it does not exceed $0.1 \mathrm{~mm} \mathrm{day}^{-1}$ except for forestland for which it reaches $-0.35 \mathrm{~mm} \mathrm{day}^{-1}$. For the changes of FVC, the sensitivity of AET in mosaic croplands and vegetation, rainfed cropland, and forestland is the most important and varies between $[0.1,0.2$ mm day $\left.{ }^{-1}\right]$ and all other land cover show much lower values (Figure 10). It reaches a maximum value of $0.16 \mathrm{~mm} \mathrm{day}^{-1}$ for forestland. There is a noticeable discrepancy between AET_SEBS obtained using LSA SAF and SPOT LAI and FVC mainly for forest cover type. In addition, mosaic cropland, mosaic vegetation, and rainfed cropland are distinguishable from the scatter plot related to FVC (Figure 10).

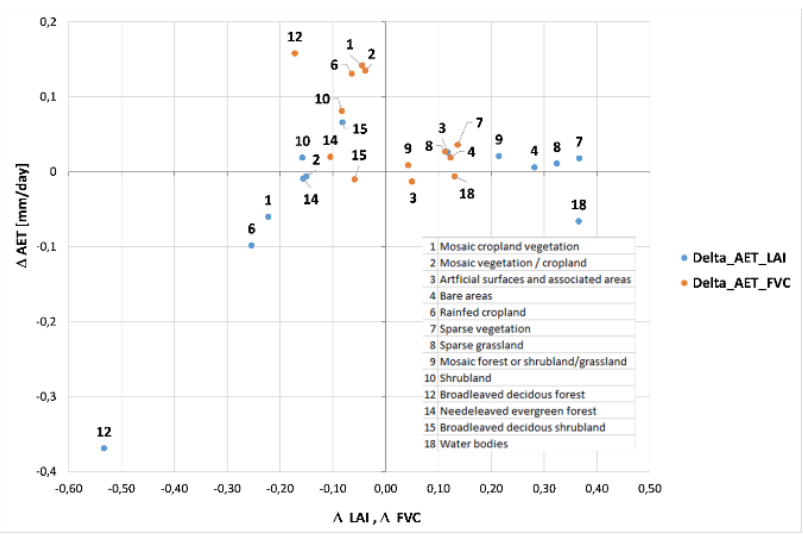

Figure 10. Scatter plot of AET change against LAI and FVC maps change aggregated by land cover types for May 6, 2010 in Medjerda Basin.

It can be concluded that the actual evapotranspiration estimated by the SEBS model is not very sensitive to the variation of LAI and FVC. The greatest variation is indicated for the occupation of the forest floor (code 12). We note an absolute bias of 0.35 and 0.16 for LAI and FVC respectively. For the other types of land use, the variation goes up to $+0.2 \mathrm{~mm} \mathrm{day}^{-1}$ in absolute value for FVC and up to +0.1 for LAI. It is, therefore, more sensitive to FVC than to LAI.

\section{CONCLUSION}

In order to estimate actual evapotranspiration (AET) using SEBS model and remote sensing technologies from different sensors and with different spatial and temporal scale, a sensitivity study of AET output was performed. The selected input data are LST, DSSF, aerodynamics parameters, FVC and LAI.

To fill gaps of land surface temperature (LST) time series, a sum of sinus functions was fitted for 10 pixels containing meteorological stations of the study area using least squares method. The sinusoidal model shows good coefficient of determination $\left(R^{2} \geqslant 0.8\right)$ values for all stations. The standard deviations of the errors of the sinusoidal model are estimated to build an interval of the variability of the LST inputs of the 10 pixels using SEBS. Moreover, LSA SAF DSSF daily data at the 10 pixels containing climatological stations compared favorably with $R_{s}$ calculated using in-situ data and based on the Angstrom formula, showing linear regressions with a good coefficient of determination $R^{2} \geqslant 0.65$. The standard deviations of the errors of the Angstrom model are estimated to build an interval of the variability of the DSSF input in SEBS for the 10 selected pixels. For the land surface temperature (LST), two levels of uncertainty of \pm one-half standard deviation and \pm one standard deviation, are used. Concerning DSSF, three levels of uncertainties of \pm onehalf standard deviation and \pm one standard deviation and \pm two standard deviations, are applied.The results show that changes of AET reach $1 \mathrm{~mm} \mathrm{day}^{-1}$ for changes of $1 / 2 \mathrm{Std}$ in LST in the 10 pixels. For changes of one Std in LST, changes of AET get at 2 $\mathrm{mm} \mathrm{day}^{-1}$ for the studied pixels. The results for DSSF show that for $1 / 2$ Std and 1 Std of DSSF, the changes of AET do not exceed $0.1 \mathrm{~mm} \mathrm{day}^{-1}$ for any pixel. For changes of two Std of DSSF, the actual evapotranspiration change reaches a maximum of $0.3 \mathrm{~mm}$ day $^{-1}$. Consequently, AET_SEBS is more sensitive to LST data than to the DSSF data as seen by pixel analysis. In addition, the roughness of momentum height $\mathrm{z}_{0 \mathrm{~m}}$ uncertainties analysis was based on the comparison of the whole map and of pixels aggregated by land cover type. The results show that the change in AET derived from land cover classification and from empirical estimation based on NDVI can reach $2 \mathrm{~mm}^{\text {day }^{-1}}$ for the forestland. For the other land use types, the variations do not exceed $0.5 \mathrm{~mm} \mathrm{day}{ }^{-1}$ per land use type. Consequently, for forestlands, a huge uncertainty about AET comes from the choice of $\mathrm{z}_{0} \mathrm{~m}$ input. Finally, the analysis of LAI and FVC inputs from LSA SAF and SPOT data shows that the changes of actual evapotranspiration with respect to LAI maps reach $0.4 \mathrm{~mm}_{\text {day }}$ ${ }^{1}$. Conversely, changes in FVC can assign changes of AET that get at $0.8 \mathrm{~mm} \mathrm{day}^{-1}$. By land use type, it is found that forestland type gives rise to greatest changes in AET both for LAI and FVC inputs. Moreover, but at a lesser degree mosaic cropland and vegetation as well as rainfed croplands come to in high changes in AET when comparing the results of the two input sources LSA SAF and SPOT.

Based on the results of the sensitivity of SEBS model to the uncertainties of various input data, the use of LSA SAF DSSF data is recommended. As LST data contain several gaps and it is the variable that produces the greatest sensitivity, it is recommended to apply the sinusoidal model to fit gaps and to validate it by in situ data if available._The choice of the method of estimating the roughness height for momentum transfer $\mathrm{Z}_{0 \mathrm{~m}}$ depends essentially on the land cover. For the forestland, the empirical model based on the NDVI presents huge uncertainties as well as the estimation based on the literature. For other types of land cover, AET is less sensitive to $\mathrm{z} 0 \mathrm{~m}$ input. Thus, it is recommended to use the empirical model because of its ability to capture the seasonal changes in land cover. In addition, AET is highly depending on FVC and LAI estimations for forestland type._Since local in-situ AET observations data in our case of study are not available, further validation is required using, for example, soil moisture data or the result of calibrated water balance models. 


\section{ACKNOWLEDGMENTS}

Authors would like to thank University of Tunis El Manar for funding a two months training of N. Abid in ITC and to thank ITC staff for their help during the training. A part of this work was funded by a grant from USAID in the framework of the PEER project "Contribution to drought identification and alert in Northern Tunisia" http://sites.nationalacademies.org/PGA/PEER/PEERscience/P GA 084029

\section{REFERENCES}

Allen, R. G., Pereira, L. S., Raes, D. and Smith, M., 1998. Crop Evapotranspiration - Guidelines for Computing crop water requirements - FAO. Irrigation and Drainage Paper 56, FAO Rome. http://www.fao.org/docrep/X0490E/X0490E00.htm

Allen, R., Tasumi, M., and Trezza, R., 2007. Satellite-Based Energy Balance for Mapping Evapotranspiration with Internalized Calibration (METRIC)-Model. J. Irrig. Drain Eng., 133(4), 380-394.

Anderson, M.C., Norman, J.M., Diak. G.R., Kustas, W.P. and Mecikalski. J.R., 1997. A two-source time-integrated model for estimating surface fluxes using thermal infrared remote sensing, Remote Sensing Environ., 60, 195-216.

Badola, A., 2009. Validation of Surface Energy Balance System (SEBS) over forestland cover and sensitivity analysis of the model. M.Sc. thesis. International Institute for Geo-information Science and Earth Observation, The Netherlands. Retrieved from http://www.itc.nl/library/papers_2009/msc/gem/badola.pdf

Bastiaanssen, W. G. M., Menenti, M., Feddes, R. A. and Holtslag, A. A. M., 1998. A remote sensing Surface Energy Balance Algorithm for Land (SEBAL), Part 1: Formulation. Journal of Hydrology 212-213, 198-212. Retrieved from http://citeseerx.ist.psu.edu/viewdoc/download?doi=10.1.1.721.2 $882 \&$ rep=rep $1 \&$ type $=$ pdf

Bhattarai, N., Shaw, S.B., JunghoIm, L.J., Niraula, R., (2016).Evaluating five remote sensing based single-source surface energy balance models for estimating daily evapotranspiration in a humid subtropical climate. International Journal of Applied Earth Observation and Geoinformation 49 (2016): 75-86. https://doi.org/10.1016/j.jag.2016.01.010

Brutsaert, W., 1982. Evaporation into the atmosphere, Reidel, Dordrecht, The Netherlands. 299p. doi: 10.1002/qj.49710945917

Champeaux, J.L., Mucher, C.A., Steinnocher, K., Griguolo, S., Wester, K., Goutorbe, J.P., Kressler, F., Heunks, C., Van Katwijk, V.F., 2000. The Pelcom Project: A 1-Km Pan-European Land Cover Database For environmental Monitoring and Use in Meteorological Models. In Proc. International Geoscience and Remote Sensing Symposium (IGARSS 2000). IEEE, PISCATAWAY, NJ, (USA), 2000, vol.5, 1915-1917. https://www.sciencebase.gov/catalog/item/505367e6e4b097cd4f cd8b17

Gibson, L. A., Z. Münch, and J. Engelbrecht., 2011. Particular uncertainties encountered in using a pre-packaged SEBS model to derive evapotranspiration in a heterogeneous study area in South Africa. Hydrol. Earth Syst. Sci., 15(1), 295-310. doi: 10.5194/hess-15-295-2011

Horvat, B., 2013. Spatial dynamics of actual daily evapotranspiration. Hrčak portal of scientific journals of Croatia. GRAĐEVINAR, 65 (8), 693-705. Retrieved from http://www.casopis-gradjevinar.hr/archive/article/837
Irmak, S., Howell, T.A., Allen, R.G., Payero, J.O., 2005. Standardized ASCE Penman-Monteith: Impact of sum-of-hourly vs. 24-hour timestep computations at reference weather station sites. Transactions of the ASAE 48.3 (2005): 1063-1077. ISSN : 0001-2351.

McCabe, M. F., and Wood, E. F., 2006. Scale influences on the remote estimation of evapotranspiration using multiple satellite sensors, Remote Sens. Environ., 105(4), 271-285. doi: 10.1016/j.rse.2006.07.006

Menenti, M., Azzali, S., Verhoef, W., van Swol, R., 1993. Mapping agro-ecological zones and time lag in vegetation growth by means of Fourier analysis of time series of NDVI images. Advances in Space Research 13 (5), 233-237. doi: 10.1016/0273-1177(93)90550-U

Menenti, M. and B.J. Choudhury., 1993. Parameterization of land surface evapotranspiration using a location- depent potential evapotranspiration and surface temperature range. In: H.J. Bolle et al. (editors.), Exchange processes at the land surface for a range of space and time scales. IAHS Publ. $\mathrm{N}^{\circ} .212,561-568$.

Roerink, G., Su, Z and Menenti, M., 2000. S-SEBI: A Simple Remote Sensing Algorithm to Estimate the Surface Energy Balance, Physics and Chemistry of the earth, Part B: Hydrology, Oceans, and atmosphere, Volume 25, Issue 2, 2000, 147-157. doi:10.1016/S1464-1909(99)00128-8

Su, Z., Schmugge, T., Kustas, W. and Massman, W., 2001. An evaluation of two models for estimation of the roughness height for heat transfer between the land surface and the atmosphere, J. Appl. Meteorol., 40, 1933-1951. doi:10.1175/1520-0450(2001) 040h1933:AEOTMFi2.0.CO;2, 2001.

Su, Z., 2002. The Surface Energy Balance System (SEBS) for estimation of turbulent heat fluxes, Hydrol. Earth Syst. Sci., 6 , 85-100. doi: 10.5194/hess-6-85-2002, 2002.

Timmermans, J., Su, Z., van der Tol, C., Verhoef, A and Verhoef, W., 2011. Quantifying the uncertainty in estimates of surfaceatmosphere fluxes through joint evaluation of the SEBS and SCOPE models. Hydrol. Earth Syst. Sci. Discuss., 8(2), 28612893. doi:10.5194/hess-17-1561-2013

Valor, E., Caselles, V., 1996. Mapping land surface emissivity from NDVI: application to European, Africa and South American areas. Rem. Sens. Environ., v. 57, p. 167-184, 1996. http://dx.doi.org/10.1016/0034-4257(96)00039-9

Van der Kwast, J., Timmermans, W., Gieske, A., Su, Z., Olioso, A., Jia, L., Elbers, J., Karssenberg, D and de Jong, S., 2009. Evaluation of the Surface Energy Balance System (SEBS) applied to ASTER imagery with flux measurements at the SPARC 2004 site (Barrax, Spain), Hydrol. Earth Syst. Sci., 13(7), 1337-1347. Retrieved from www.hydrol-earth-systsci.net/13/1337/2009/.

Wagle, P., Bhattarai, N., Gowda, P.H., Kakani, V.G., 2017. Performance of five surface energy balance models for estimating daily evapotranspiration in high biomass sorghum. ISPRS Journal of Photogrammetry and Remote Sensing 128 (2017): 192-203. https://doi.org/10.1016/j.isprsjprs.2017.03.022.

$\mathrm{Xu}, \mathrm{Y}$ and Shen, Y., 2013. Reconstruction of the land surface temperature time series using harmonics analysis. Computers \& Geosciences 61, 126-132. doi: 10.1016/j.cageo.2013.08.009 